\title{
The Metaphor of Circle: Stanislavski, Phenomenology of Roundness and High Yoga
}

\author{
Sreenath Nair, University of Lincoln
}

\begin{abstract}
:
Stanislavski's Eastern influence and his persistent fascination with Yoga is an established area of research. Stanislavski has two major yogic influences in the System: Hatha Yoga and Raja Yoga. The first is about training the body through postures, movements, stances and breathing exercises to make it active, relaxed and energetic. The second includes a range of exclusive practices on concentration and visualization that are an integral part of the actor's creativity. However, in the current research, there is a clear lack of a comprehensive practical method that informs Stanislavski's use of yogic practice in the System: what specific yogic exercises were used and what synergies were developed in the training? Scholars have, so far, only explored Stanislavski's literary legacy of his encounter with yoga, identifying the Sanskrit terms appeared in his writings such as prana for breathing and the Indian anecdotes he used when answering the questions of his students. Focusing on the metaphor of the circle, the phenomenology of roundness and the Deleuzian notions of 'the invisible forces of sensations' and 'the body becomes an event itself', the present study, for the first time, offers useful insights into the fundamental principles of yoga and their methods of practice as a way of developing a new training to understand the significance of Stanislavski in the $21^{\text {st }}$ century.
\end{abstract}

\section{Key Words:}

High Yoga

\section{Prana}

Sensory-sensual Space

Lived experience 


\section{Circle Walk}

Phenomenology of Roundness

The metaphor of the circle remains a dominant theme in Stanislavski ${ }^{1}$ when he speaks about the creative life of the actor. Working persistently on the idea of the circle, Stanislavski not only developed some crucial insights on the organic correlations between the actor's concentration and imagination but also created a number of rehearsal techniques exploring the psychophysical links between the actor's memory, breathing and her creative readiness. Wegner records the appearance of several critical terms of the "circle" in Stanislavski in the stenographic notes of his lectures to the students of the Opera Studio, 1918-1922, in which he continuously used "creative circle" and "creative circle of public solitude" to describe the actor's creative inspiration. ${ }^{2}$ The elusive moment of the absorption of the circle in Stanislavski appeared again, when he analyses the performative moments of the actor on the stage, such as "experiencing" (perezhivanie), "public solitude", "inspiration", "creative mood", "subconscious" and "superconscious". ${ }^{3}$ These words are representative of the Stanislavski System clearly suggesting a trajectory of practice developing from the "creative circle of public solitude" to the abstract ideas of "superconscious", a term at which Stanislavski arrives repeatedly throughout in the System. Olga Knipper was distressed by Stanislavski's 'odd sounding terms such as 'circle' and 'invisible irradiation of will and feeling".. ${ }^{4}$ As Vera Solovovia, a member of the first studio from 1911-1913, recollects in an interview:

Stanislavski, Eugene Vakhtangov and Michael Chekov were all interested in yoga and employed in their teaching. We used it in our exercises in the First Studio ... we worked a great deal on 
concentration. It was called 'To get into the Circle'. We imagined a circle around us and send prana rays of communion into space and to each other. Stanislavski said, 'send the prana there' - I went to reach through the tip of my finger-to God-the sky-or, later on, my partner. I believe in my inner energy and I give it out - I spread it. ${ }^{5}$ David Magarshack, in a similar fashion, records that

At the time Stanislavski was interested in Hindoo philosophy and especially in the yoga system of abstract meditation and mental concentration, which supplied him with one of the most important elements of his own system-the circle of public solitude consisting of a number of large and small 'circles' into which the actor has to withdraw in order to keep his attention concentrated on the stage and not on the audience. ${ }^{6}$

Lee Strasberg's diary of 1924-1925 contains a full page of Sanskrit terms relating to emotions and emptiness derived from the Natyasastra such as bhava, vibhava, sattvabhava and sunyata ${ }^{7}$ All these accounts undoubtedly conclude that Stanislavski not only drew vehemently on Hatha Yoga and Raja Yoga to develop his System but also handed down the legacy to the next generation of his students to lay the foundation for the $20^{\text {th }}$ century actor training.

For Stanislavski, the movement of prana creates an inner rhythm for the actor. He taught the actors "the law of correct breathing, the correct position of the body and concentration", ${ }^{8}$ all come from his encounter with the practice of yoga that he acknowledged with great admiration stating that "my whole system is based on this" and that the "yogis give much practical advice in these realm ... [when] they approach the unconscious through conscious, preparatory devices, from the body to the soul, 
from the 'real' to the 'unreal'". ${ }^{9}$ Scholars have undertaken enormous initiatives (William Wegner, 1976; Sharon Carnicke, 1989 \& 1998; Andrew White, 2006 and Jean Benedetti, 2008) to recover the literary legacy of the practical application of the "actively suppressed" and "willfully overlooked" aspects of Yoga in the System. Despite these attempts, a clear practical understanding of the core of Stanislavski's interaction with the practice of yoga remains unexplored until today. Focusing on the metaphor of the circle, I initiate this exploration of the practical base of the Yoga's meeting point with the System by asking the following questions: what is the importance of the circle in the practice of yoga? How are Stanislavski's techniques, like public solitude and circle of attention, connected to the yogic notion of embodied cyclical movements? What psychophysical techniques are available today for us to develop new practical insights into Stanislavski to better modify and enhance his practical applications of yoga in the System for the $21^{\text {st }}$ century?

\section{Mental trapdoor in Stanislavski}

A substantial body of documentary evidence has become available in Stanislavski studies in recent years that clearly shows Stanislavski's fascination with Hatha Yoga and Raja Yoga, especially, the ways in which he adapts relaxation, breathing techniques, concentration, visualization and observation. According to Carnicke, Stanislavski's integration of Yoga techniques is a rigorous "redirecting" of the Yoga's "inward techniques outward" in order to develop a reliable practical approach for the actors "to escape the realistic and naturalistic boundaries in artistic expression". ${ }^{10}$ Deeply informed by Raja Yoga, Stanislavski did believe that the actor's creative state has an interlocking mechanism with the subconscious mind, the dynamic which can be unlocked through the conscious application of meditation techniques. Stanislavski 
imagined a "mental trap-door" in the actor through which he can "throw" a "bundle of thoughts" into the unconscious mind to get them processed as "creative acts" in an actor's work on the role. ${ }^{11}$ This clearly suggests that the choices and decisions of an actor in the creative process, according to Stanislavski, come through naturally without any intellectual efforts. The metaphors of the "trap-door" and "throwing bundle of thoughts" on the one hand suggest the need for a thoughtless, relaxed and clear mind in the actor during her creative process. On the other hand, it emphasizes the need for an amplified and intense level of attention, concentration and observation in the actor to listen to the unconscious mind when the "bundle of thoughts" is "handed back" 12 thoroughly analyzed and classified. Dropping off thoughts, therefore, is a crucial method both in Stanislavski and Yoga because it is a powerful way to access the creative potentials of the unconscious.

Stanislavski prescribed asanas (postures) and pranayama (circular breathing) exercises from Hatha Yoga in his First Studio. He developed exercises to intensify the actor's concentration and attention and explained public solitude as a state of mind where "you must shut things out". ${ }^{13}$ It is called 'public' because a thousand eyes are on the actor; it is 'solitude' because the actor is cut-off from them by a small circle of attention, "like a snail in its shell". ${ }^{14}$ What is this state of "shutting things out" from us, simultaneously, when we are aware of everything around us? What is the experience of having solitude and being in public, at the same time, and how can one belong to these two different places at the same time? While explaining the concept of public solitude, anecdotally, Stanislavski answers these questions, of an Indian Maharaja, who looked for a potential minister by asking candidates to carry a pitcher full of milk around the city walls and under the testing fire of his soldiers, without spilling a drop. ${ }^{15}$ In a similar fashion, Carnicke mentions Yogananda's anecdote of a young man who shifts himself 
into a "transforming silence" in the middle of the city of Calcutta where pedestrians, passing trolley cars, automobiles and cycle rickshaws all suddenly become noiseless. ${ }^{16}$ What is distinctive in these anecdotes is the careful application of concentration, focus and undivided attention to physical actions: the potential minister and the young man reoriented their muscular energies and centred them on their actions rather than spreading them all over the places. For Stanislavski, concentration and attention are of two vital psychophysical tools for the actor due to the "closeness of the crowd" and the actor's creative moments constantly being watched by the audience. ${ }^{17}$ Considering the very nature of the art of acting being an interactive process between the actor and the audience, there is a potential danger that the actor could lose her spontaneity during the performance. Getting into the "circle" of undivided attention, into the sphere of public solitude, in Stanislavski's opinion, therefore, becomes a fundamental preparatory device for the actors. Stanislavski believed that there should be regular exercises for actors to improve their power of concentration for a "truthful" performative transformation.

\section{The Metaphor of the Circle in Stanislavski}

The class on Concentration and Attention, which took place in Marya's apartment, offers some valuable details about Stanislavski's methodology of practice for public solitude. ${ }^{18}$ The students were asked to observe the objects around them, and they did so. While doing this, they initially observed the "split" between the subject and the object. The object was always positioned 'outside' of the subject who was looking from 'inside'. The objects were everywhere and always attracted the attention of the subject. Stanislavski insists a different way of learning to "look and see"19 referring to the eyes as "the mirror of the soul" and distinguishing the experiential difference between 
"looking" and "seeing": when the actor's eyes "look" and "see", they attract the attention of the audience, ... whereas, vacant eyes direct the audience attention away from the stage. ${ }^{20}$ Stanislavski draws the circle of light with objects in it. Actors looked at the objects in the circle of light and described them in the darkness as a way of remembering them while beginning to learn how to look and see on stage. As the circle of light grows out bigger from a tabletop to include few objects in the room, then the room itself and slowly more than one room of the entire building, the actors also widen the circle of their attention. In order to sharpen their concentration, the time given to the actors to observe the objects in the pool of light has been reduced from thirty seconds to three-to-five seconds. Stanislavski introduced three circles of attention and three focal points throughout these exercises--small, medium and large. There are immediate objects and immediate focal points as well as the mid and distant focal points of 'looking' and 'seeing' that correlate within the small, medium and large circles of lights. The actors moved their focal points and 'circles of attention', time-to-time, from the immediate to distant and from small to large. When the actor is in the pool of light, she "cuts-off from the outside" world to bring intense focus on the stage. Stanislavski explained this state as 'public solitude' of the actor.

This exercise looks like more of a mental task than a psychophysical momentum. The only physical means for a Stanislavski actor to achieve the public solitude is to 'look' and 'see' objects in the pool of light through various focal points and circumferences of the circles of lights, the act which is more psychological than physical. How does an actor, then, develop psychophysical reflexes while moving between these circles if the exercise is not supported by physical means? As Stanislavski addresses the point, "this can only continue as long as you are able, mentally, to hold onto the circumference firmly". ${ }^{21}$ This clarifies the point that the 
public solitude has purely been conceived as a mental task rather than a comprehensive psychophysical approach to the actor's concentration. As we see in Benedetti's account, the students struggled throughout the exercise as their "concentration slips out of control and dissolves into space". ${ }^{22}$ What is apparently missing in Stanislavski's practice on the circle of attention is the physical means, which would help the actors to control their muscular energies to prolong their internal focus. Moreover, the spatial dimension of the circle is reduced to a linguistic mental space compared to an embodied-sensory realm where the actor constitutes an interactive "sensory-sensual space" 23 through the practice of the body. Although Stanislavski shows a profound understanding of the fundamental principles of the psychophysical involvement of the actor's concentration, his actual practice does not explore the entire scope of it. There are a number of questions to ask here before I continue with my investigation: how does an actor, standing in the middle of a pool of light, achieve the same degree and level of the concentration that only a yogi can achieve as reflected in Stanislavski's anecdote? Are there psychophysical methods available in Yoga through which the actor can kinetically experience the circle of attention to control their muscular energies to intensify the internal concentration without the focus being distracted and dissolved into space? A careful reconsideration and application of the High Yoga ${ }^{24}$ techniques will close this gap.

\section{High Yoga: Some Reflections on Practice}

Mind control and abandonment of thoughts are central to yogic practice (Y.S I:II) ${ }^{25}$ Dropping of thoughts is an effective way to control the activities of the mind since thoughts form much of the activities of the mind. According to the practice of high yoga, there are two constructive ways of controlling one's thoughts: controlling eyes 
and controlling breath. The mind wanders as long as the eyes wander and when the eyes are fixed, the breathing and the mental activities simultaneously slow down to an observable stillness. High yoga offers a range of psychophysical techniques involving eyes and breathing in order to intensify the concentration and control over the wandering mental activities. The following high yoga exercises ${ }^{26}$ will demonstrate a careful integration of the eyes and breathing into the practice of concentration:

\section{Gazing exercise - Stage One}

There are two modes of gazing, inner gazing (anthar tradaka) and outer gazing (bahir tradaka), practiced at three different stages. The stage one involves outer gazing and the stage two involves inner and outer gazing, whereas the stage three involves only inner gazing. All three stages and three modes of practice integrate breathing exercises at various stages:

Chose an object of your gaze that can be a spot on the wall, a flower, a symbol one prefers or own eyes reflected in the mirror. Sit in the most comfortable position, on the floor or on the chair, to practice the following steps:

- Place the object of gaze parallel to the eyes.

- Sit in a comfortable position.

- Close the eyes and breathe slowly and deeply activating the diaphragm until the body is relaxed.

- Then widely open the eyes and gaze at the object in front without blinking or moving the eyeballs. 
- Hold the position as long as you can; blink only when you feel that your eyelids are heavy. Repeat the exercise.

Continue the exercise for two to three minutes. Do not strain the eyes or take it too hard. Many people cannot resist blinking, but continuous practice will enable a longer period of holding the gaze without blinking. Centering the awareness on the object of the gaze will slowly enable to identify a lack of awareness of one's body. The mental activities will naturally slow down or reduce to a state of stillness, with breath being centred and internalized ${ }^{27}$ without any physical efforts.

\section{Gazing Exercise - Stage Two}

At this stage, the internal gazing and external gazing can be done one after another with the same preparations prescribed above:

- Practice outer gazing exercise for two to three minutes as prescribed above.

- Be aware of the breathing while continuing the outer gazing exercise. Imagine you are drawing the air right from the object of the concentration to the centre of the eyebrows up to the back of the head. The air returns to the object when you exhale. This makes an imaginary circle. There are two objects of concentration, operating simultaneously: the object and the breath. The object is connected to breathing, both being part of an undivided breathing circle of attention.

- Listen to the sound of the breathing and continue the exercise for two to three minutes.

- Close the eyes and gaze at the after-image of the object. 
- See the object as clear as you see in the outer gazing exercise and continue drawing the air from it and return it the same way. Imagine clearly the circle of air moving between the object and the eyebrows and back before returning to the same source.

- Imagine pulling the image while breathing in and push the object away while breathing out.

- Continue the exercise for two to three minutes, and then close the eyes.

Eventually, the practitioner will be able to focus on four different things: the object, the movement of the object, the breathing and its sound, without any interruption.

\section{Gazing Exercise - Stage Three}

At this stage, the gazing exercise involves only internal gazing as follows:

- Sit in a comfortable position and close the eyes until the end of the exercise.

- Concentrate on the eyebrows, and breathe deeply and slowly, activating the diaphragm until the body becomes relaxed and without any movement

- Visualize the object internally as original as possible. It may fade away but do it again and don't move to the next step until you are successful.

- Gaze at the inner image and repeat the breathing exercise in the same way as at stage two including listening to the sound and moving the images back and forth while inhaling and exhaling.

- Imagine the circle of breath back and forth from the object and continue

- Continue the exercise for five to ten minutes.

- Concentrate on the breathing and stop listening to its sound. 
- Concentrate fully on the inner image and go into its details such as the size, shape or color.

- Continue the exercise for five to ten minutes.

The exercises above undoubtedly show the importance of the integration of eyes and breathing in concentration. They are used in a number of specific ways to control the mental activities. A range of psychophysical properties of the body such as breathawareness, stillness of the body and eyes are carefully employed in these exercises to create an ongoing field of concentration in order to create the inner image of the object of your concentration. The most remarkable aspect of the exercise is the creation of the imaginary circle of attention mediated by breathing in which the object is kept alive and animated back and forth through the ongoing internal circles of the in-breath and out-breath. Inner visualization and imagination, in this way, are of crucial importance to the exercise at all three stages that are fundamentally associated with the practitioner's undivided concentration, which is a living momentum established in the ongoing circles of breathing.

The conceptualization of space and the body as a single inseparable unit (samyoga) of constantly evolving psychophysical momentum is the foundational principle of yogic practice. Space is not separable from the body and the very existence of it can only be measured in terms of time, especially, breathing as time. This point of departure is taken in Stanislavski. It is important to note that in Stanislavski, in order to create the inner concentration, the circle is drawn outside of the body, in the physical space and then the actor is placed in it. In yogic practice, however, concentration is the result of a mind/body union where the body becomes the space in which the circle is drawn within the ongoing cycles of breathing. Obviously, there are clear parallels between 
Stanislavski and the yogic gazing exercises, mainly the ways in which the eyes and breathing are integrated in their practice. Stanislavski constantly mentions 'looking', 'seeing' and 'breathing' throughout in the exercise to 'consciously tap' the unconscious domain of the actor's creative state through the circle of attention. In the yogic gazing exercises, concentration is the result of a careful synthesis of practice of eyes, breathing and the body in the realm of space and time. In this way, in yogic practice, the physical apparatus of the circle of attention is internalized as an organic 'lived experience', the psychophysical approach that is apparently missing in Stanislavski's circle of attention.

Placing the body in the field of space and time, Merleau-Ponty says:

I am not in space and time, nor do I conceive space and time; I belong to them, my body combines with them and include them. The scope of this inclusion is the measure of that of my existence. $^{28}$

Through the practical involvement of the body, according to Merleau-Ponty, the spatial and temporal dimensions of the visible world begin to unfold. He further contemplates that it is "my movements and the movements of my eyes" 29 that makes the world visible. The act of looking cannot be detached from what is being seen and experienced.

\section{The image of the Circle in Yoga}

In extending the investigation beyond the level of practical exercises, the metaphor of circle as a "sensory-sensual space" becomes fundamental to the philosophical teachings of yoga. The circle in the form of the wheel represents the spatial and temporal relationship of Indian cosmology. The wheel is the pre-eminent symbol of time with a stationary centre, which allows movement and change, creation [and] time. ${ }^{30}$ Spacetime expands constantly by the movement of the wheel. The image of the wheel refers 
to the movement that is repetitive and cyclical. ${ }^{31}$ In Indian thoughts, the graphic representation of the wheel connects the centre and the circumference, the microcosm and macrocosm, the constantly evolving interconnected organic whole of the natural existence through space and time. ${ }^{32}$ Yoga represents this speculative thought bringing the complex relationships between the body and senses, the in-breath and out-breath, the inner world and outer world, the movement and stillness, the visible and invisible, and the physical and tactile through constant practice and repetition of the performative act of the body.

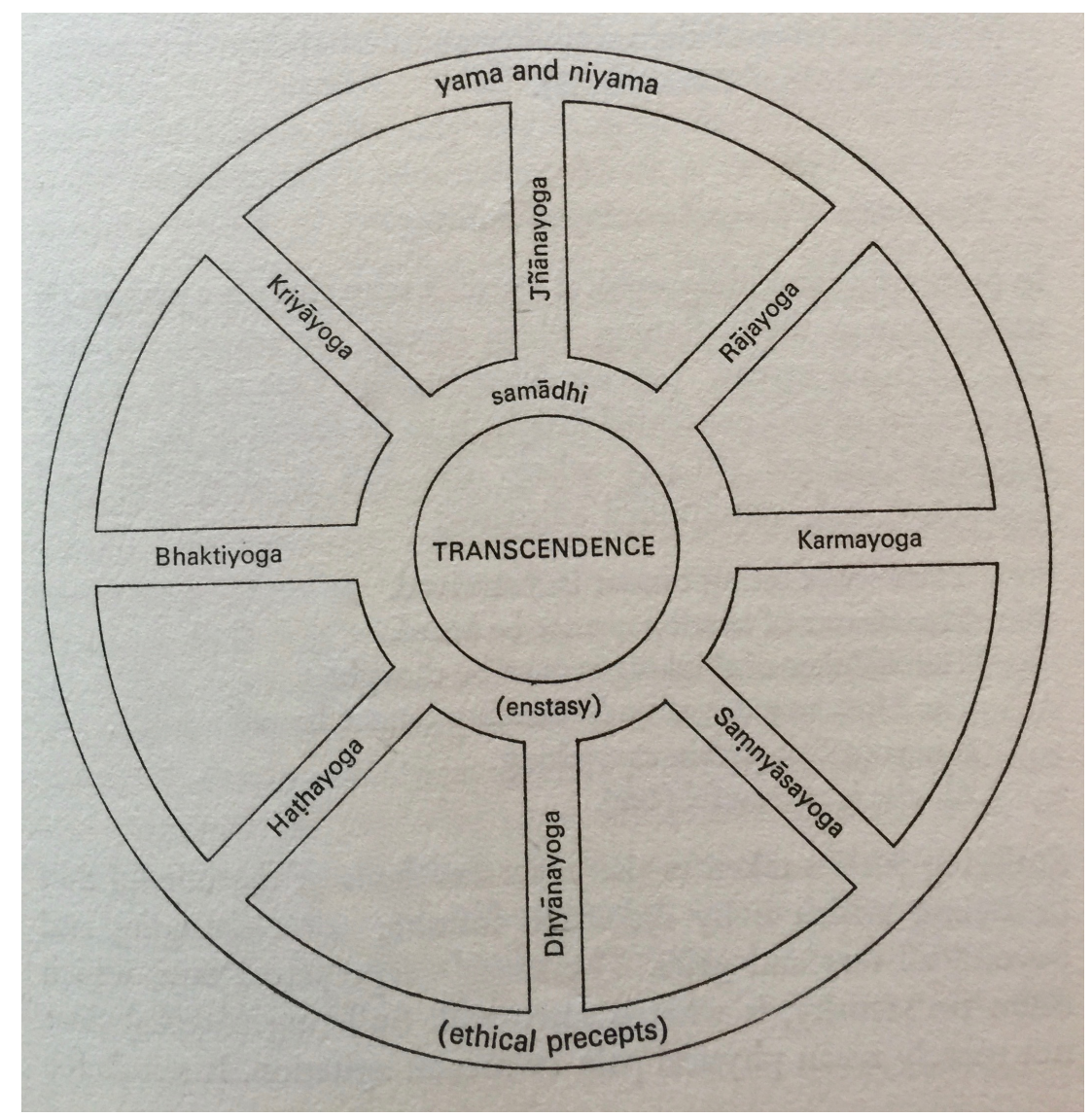

Figure 1: The wheel showing the system of Yoga as a wheel combining different methods into a unified field of practice. ${ }^{33}$ 
According to Irigaray, the yogis care about the harmonious maintenance of the life between the body and the universe as cosmic nature through the practice of concentration through voluntary breathing. ${ }^{34}$ In The Yoga-Sutra, Pathanjali repeatedly talks about the importance of concentration in yogic practice implying that appropriate techniques should be used for the practice of concentration. ${ }^{35}$ The circle constantly appears as a fundamental image of practice of concentration in yoga. The concept of chakra, the psycho-physiological centres of the body, is imagined as energy wheels in the body. The repetition of yogic postural exercises with the left and right sides of the body creates a cyclical pattern of the recurrent reappearance of the body. Above all, the synchronization of the rhythmic breathing involving the left and right nostrils with the physical postures combining the left and right sides of the body creates another layer of 'lived' concentration embedded in the dynamic circle of ongoing in-breaths and outbreaths. ${ }^{36}$

Circle Walk (chankramanam) ${ }^{37}$ is another exercise practiced for concentration: the practitioner is asked to walk in a circle rhythmically anti-clockwise with a repeating sound or syllable synchronizing with the left foot and right foot in turn and also with the head forward and the eyes looking down without 'seeing' anything. Another variation of the same exercise is also available in which the practitioner is asked to rotate anti-clockwise concentrating on the navel. Specific instructions were given to the position of the hands and eyes keeping it vacant and emotionless during the course of the practice. The circle, in this way, as the metaphoric representation of the kinetic properties of the bodily practice, remains fundamental to the substratum of yogic philosophy and practice.

\section{Phenomenology of Roundness and Embodied Imagination}


Bachelard, in his discussion about the phenomenology of roundness, says: Images of full roundness help us to collect ourselves, permit us to confer and initial constitution of ourselves, and to confirm our being intimately, inside. ${ }^{38}$

He further states that the imagination of roundness is very closely connected to being and when something is isolated it becomes round that is concentrated upon itself ${ }^{39}$. One's own imagination of the roundness, in this way, interacts deeply with a profound level of concentration and awareness of being detached or isolated from the world out there while simultaneously engaging with it. Stanislavski advocates for a similar psychophysical condition in the actor that he calls public solitude where you shut things out in the midst of a crowd to begin a creative journey of the art of acting. Needless to say that there is a psychophysical journey in the actor to imagine the circle, as a snail in its shell, borrowing Stanislavski's term, and this imagination can only be materialized truthfully, when the actor is given adequate psychophysical tools to work with in the process of her "ephemeral art" ${ }^{40}$ Let me bring another example to take this discussion to the next level: 


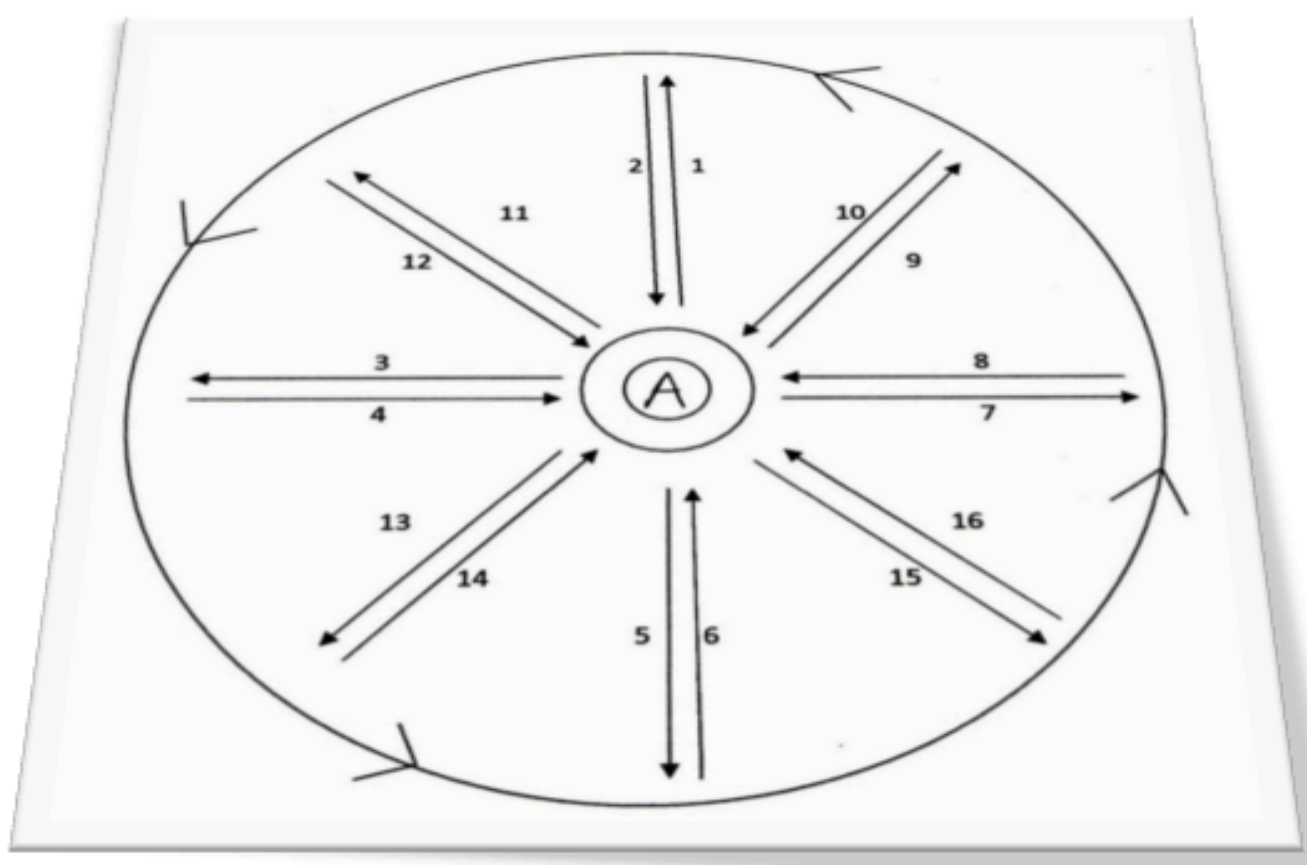

Figure 2. Tattu-Marma, a rare martial art form of Kerala in which the martial artist creates a circle of movements to create concentration.

The diagram represents the geometrical pattern of a series of movements practiced in Tattu-marma ${ }^{41}$ a rare martial art of Kerala. Designed in the form of a wheel, the movement comprises two circles and a number of spokes connecting them in proportion. The small circle in the middle is the axle position of the wheel and the outer circle is the periphery of the wheel marking the edge of the movement. Each spoke is a pathway in which the martial artist moves up to the periphery and returns to the centre. A pathway comprises two movements, moving away from the axle, coupled with a swift turn of the body followed by an opposite movement towards the axle. The left foot is synchronized with the left hand, the right foot is synchronized with the right hand and the bipolar movement of the body is synchronized with the bipolar movement of breathing. The left and right hands are synchronized with the left and right feet and 
the left and right sides of the body are synchronized with various dimensions of the body and its martial postures. As the movement progresses through the offensive and defensive positions, a martial rhythm is created in the wheel. The bipolar movement of the feet coordinates with the bipolar movement of breathing that creates a single unity of rhythmic circles in the martial wheel. The foot is placed at the axle position of the wheel; a breath is taken when the foot moves and the wheel slowly moves in the anticlockwise direction to create a field of kinetic energy in the wheel.

The movement is taught initially in a small circle of four spokes, then in a medium circle of eight, and finally in a large circle of sixteen. The student has always been asked to look at the movement of the hand while following specific instructions on breathing during the attack. There are expanding and contracting circles around the martial artist--moving from small to large and vice versa. The circumference of the wheel does not change, but the number of spokes will define the size of the wheel, the smaller number of the spokes determining the smaller wheel and vice versa. After completing each spoke, the student will return to her comfort zone, which is the small circle. This circle is the most comfortable and secure zone where the student stands neutral with full readiness and being aware of the entire surrounding. In moments of attack and defence, the student will be in the pathway of a spoke, going out or coming in, and the direction of that movement will be depending on the position of the enemy. The ultimate aim of the movement technique is to develop an intense level of concentration in the practitioner, which is essential for the precise application of the martial knowledge. A fully trained martial artist can imagine a circle of attention always around her and the wheel moves wherever she goes, forming an intact and intense sensation of concentration. Here, the concentration becomes physical and sensory or, in another way, the imaginary recreation of the circle around the martial artist obviously 
will bring her bodily memories of 'sensory concentration'. In a Lefebvrian sense, a circle is drawn entirely within the "practico-sensory realm" 42 of the 'lived experience' of the martial artist in which the space of the circle is established through repetitions and recurrences of physical movements that include the specific ways of 'breathing', 'looking' and 'seeing'. A broad spectrum of the spatial dimension of the martial wheel, in this way, is reimagined through the bodily application of the circle.

In Lefebvre, time is closely connected with space in order to explain temporality. He proposes two types of repetitions: cyclical and linear. ${ }^{43}$ The cyclical repetition is organised according to phenomena such as days and nights, seasons, generations, youth and age, all following the law of nature, whereas the linear one is mechanical, en-framed and constrained. For him, the time-body relationship involves a great deal of repetitions of physical actions that are embedded in rhythm. Employing Lefebvrian rhythmanalysis, the living body of the martial artist, through constantly developing cyclical movements in the martial wheel, dismisses any separation between space and time, meaning that the physical movements as the temporal dimension of the body create spatial dimension of the wheel in which the rhythmic movements are repeated to create the circle of attention. Time has the same ontological status as space here since the physical existence of the wheel is created and reimagined through the kinetic engagement of the body located between the mind and the body and subject and object. $^{44}$

In short, in order to understand the Indian psychophysical approach to the actor's concentration practiced in yoga and martial art, as demonstrated above, I propose three main features: 1) inter-corporeal connectivity between bodily properties such as eyes, hands and respiration to create a shared bodily idiom 2) the intersubjective spatiality in which the internal and external spaces are unified in the living 
body 3 ) inter-kinetic modalities that combine multiple temporal functions of the body such as rhythm, memory and repetition of physical actions. The body, in this way, becomes the field of a dynamic process of actualizing the imperceptible forces through embodied imagination: the circle as the physical feature of space is embodied as 'sensation' in all the above examples. ${ }^{45}$ The sensation of the circle in the field of concentration is not a material spatial structure, but the embodied evocation of the spatial energy of the circle through the repetition of physical techniques. As Roland Bogue observes, the boundary between the internal and external does disappear and what remains active in this process is the constant interaction "between invisible forces and visible bodies, the body of sensation rendering visible the invisible forces that play through bodies". ${ }^{46}$ In Deleuzian terms, it is "one through the other" or "one in the other" where the body becomes an event itself. ${ }^{47}$ This is precisely the point where yoga comes into the System with preparatory methods that guide the actor's journey "from the physical to the mental, from the real to the unreal, from the naturalist to the abstract". ${ }^{48}$ In the Deleuzian sense, what Stanislavski enunciates repeatedly throughout the discussion is "the invisible forces of sensations" that extend beyond the bio-logical and psycho-logical realms of the actor's creativity: a preparatory work that enables "one through the other" or "one in the other". 49

\section{Circle of Attention: Practice (re) Considered}

A careful reading of Stanislavski undoubtedly shows his persistent interest in working with the imperceptible forces and unknown territories of the actor's creativity. Stanislavski used the term superconscious synonymous to spontaneity and inspiration, the fundamental principles of the actor's creative inner state, suggesting that "the superconscious starts where reality or rather ultranaturalism ends" ${ }^{50}$ For him, in order 
to establish the right creative state on stage, the actor should take care of the superconscious and inspiration before starting to think about them. All the techniques the actor learns, including the given circumstances, must become the second nature of the actor. "Only then will inspiration decide to open its secret doors". ${ }^{51}$ As Stanislavski suggests, intuition is inaccessible to intelligence, and it is accessible only to feelings-not to thoughts but to the creative experience, not to the actor's techniques but to the deeper and complex levels of artistic nature. Stanislavski encounters a problem here that "the superconscious stops where artistic conventions begin" ${ }^{52}$ but we clearly see that the actors cannot play without artistic conventions and techniques. So, it is not the one or the other way approach. For Stanislavski, finding a balance between the inspiration and technique is a big question for the actor. As he observes, "most actors restrict themselves to superficial experiencing and the audience is satisfied with surface impressions". ${ }^{53}$ But Stanislavski seems to be clear about the possibility of actors working with spontaneity and inspiration stating: "those who approach the superconscious directly and try technically to copy those outward forms of things only can [have] access to intuition, fall victim to the other extreme, vulgar stock-in- trade, not inspiration". ${ }^{54}$ In another way, only the actor who can directly access the superconscious at the same time as playing the artistic conventions can access the 'inspiration' in its true sense. Using Stanislavski’s own analogy, “an axe cannot make a fine sculpture, so the actor's simple techniques cannot convey the subtleties of creative nature". ${ }^{55}$ It is evident throughout the discussion that Stanislavski was in search of an unknown territory in the actor's creativity where the attention is undivided and creatively spontaneous and intuitive. 
To summarise, the metaphoric image of the circle continues to be a key element of practice in Stanislavski and High Yoga. Within the broader context of the discussion presented above, I propose the following practical approach to the circle of attention exercise Stanislavski recommended. The workshop model includes three distinctive phases: the phase one involves the actor's work with concentration at an individual level where a range of preparatory exercises developed from yogic and martial exercises will be given to develop focus, visualization, imagination and the lived experience of public solitude. Following these foundational exercises at an individual level, the second phase will be an interactive workshop involving objects and space, which will influence the actor's concentration and reflexes in group improvisations. Most of the exercises at this phase will help the actor to unify the physical and internal spaces through breathing, visualization and imagination. The final phase of this exercise will include scene work encouraging the actor to work with intuitive responses and commands sending and receiving between the actors and the actor and the audience. Correlating with the Indian psychophysical principles such as inter-corporeal, intersubjective and inter-kinetic presented in the yogic and martial practices, the proposed workshop model integrates the practical application of those principles at the level of embodied imagination in the actor's work. A breakdown of these practical elements will further clarify the significance of the new workshop model:

1. Actor's individual work with the circle of attention:

- A range of preparatory exercises derived from yogic, Indian martial and performance practices including exercises for eye, hands and breathing to develop public solitude. 
- The Tattu-marma martial wheel diagram will be used as the floor plan work with the embodied circle of attention. In completion of the exercise, the actors will be able to visualize three ranges of kinetic circles (small, mid and large) surrounding her activities in the space.

- These preparatory exercises will continue until the actor is fully capable of visualizing the circle of attention through embodied imagination as a wheel of energy.

2. Actor's work with objects, space and people:

- The Tattu-marma floor plan will be used to work with reflexes and energy levels of the actor when people and objects enter into the actor's field of energy. This interactive workshop will involve objects and people within the specific locations and pathways in the floor plan.

3. The actor will be working with the small, mid and large ranges of circles through improvisations with objects, situations and scenarios. It is a way of integrating the world of play into the actor's personal world, into the imaginary fields of sensations and energies, to influence, control and act upon the events taking place within the circle of attention.

4. Actor's work with scene:

- Actor works with text and with given circumstances from the viewpoint of the circle of attention to enhance the stage presence.

- Actor's work with scene encountering blocking and movements to listen to the "silent commands" $" 56$ from other actors.

- Actor's work with instincts rather than conscious reasoning to bring spontaneity and imagination in acting. 
The proposed workshop model is an attempt, for the first time, to introduce a new range of psychophysical resources, hitherto unknown in the field of yogic and martial practices, to fully explore Stanislavski in the $21^{\text {st }}$ century. The enquiry will develop new synergies of practice in the System "where the real ends" 57 and where the actor's body delivers invisible forces through the visible rendering of deep creative sensations.

\section{Notes:}

1Wegner,"The creative circle", 85-90. This seems to be the first English publication exploring Stanislavski's link to Yoga and its application into the System. Wegner in this essay makes the connection between the "circle" and the actor's creativity suggesting that Stanislavski derived this concept from Patanjali and Tantric Buddhism (89).

2 Ibid, p. 86

${ }^{3}$ Carnicke, "The Life" 3-14.

${ }^{4}$ Magarshack, Stanislavski: A Life.

${ }^{5}$ Carnicke, "The Life", 86.

${ }^{6}$ Magarshack, Stanislavski: A Life, 304, 306.

7 Tcherkasski, Stanislavsky and Yoga, 37.

${ }^{8}$ Carnicke, "The Life", 13.

${ }^{9}$ Ibid., 13.

${ }^{10}$ Carnicke, Stanislavsky in Focus, 176.

11 Ibid.

12 Ibid.

13 Benedetti, An Actor's work, 102.

14 Ibid., 99-102.

15 Wegner, "The creative circle", 87 and Carnicke, Stanislavsky in Focus, 178)

16 Carnicke, Stanislavsky in Focus, 178.

17 Benedetti, An Actor's work, 93.

18 Ibid., 86-118.

19 Ibid., 91.

20 Ibid., 95.

21 Ibid., 101.

22 Ibid.

${ }^{23}$ Lefebvre, The Production of Space.

${ }^{24}$ High Yoga is the term I use in this article to differentiate the yogic techniques I employed in the workshop model I propose in the essay. Generally speaking, yoga is primarily understood as a series of physical exercises linking various bodily postures to master the muscular movements and the overall flexibility of the body. These exercises are largely derived from Hatha Yoga, the most popular system of yoga promoted internationally by Krishnamacharya (1888-1989), Ashtanga Yoga of Pattabhi Joshi (1915-2009) and B. K. S. Iyengar (1918-2014). 
Raja Yoga refers to another branch of yoga dealing with control over the mind and emotions mainly promoted by Swami Vivekananda (1863-1902). Breath control through pranayama is central to both Hatha Yoga and Raja Yoga and the practice of both informed Stanislavski's System. The teachings of yoga extend beyond what is known to us and, in this particular context, I use the term High yoga to refer to some of the exclusive yogic practices mentioned in the essay.

${ }^{25}$ According to Patanjali, the author of the Yoga Sutra, yogic practice enables the practitioner to stabilize mental activities through controlling fluctuating thoughts (Yogas-citta-vrtti-norodhah (I:II).

${ }^{26}$ Several gazing exercises can be found in different schools of Yoga known as

Tradaka. The variations of the same exercise can be found in Hatha Yoga, Raja Yoga and Kriya Yoga, but all they have is the same objective of establishing a deeper level of uninterrupted concentration in the practitioner.

27 See Nair, Restoration of Breath, 2007 for details of internalised breath.

28 Merleau-Ponty, Phenomenology of Perception, 140.

${ }^{29}$ Ibid., 7.

${ }^{30}$ Malville, "Astrophysics, Cosmology", 140.

31 Vatsyayan, The Square and Circle, 7-14.

32 Ibid., 13-14.

33 George Feuerstein's (1975) above chart shows how different schools and systems of practice have the same objective. Each school has an individual pathway of practice leading to a unified body/mind experience.

${ }^{34}$ Irigaray, Between East and West, 31 and 62.

${ }^{35}$ Feuerstein, The Yoga-Sutra, (YS: I: 32), 47.

36 Jonathan Pitches talks about the notion of breathing ('inspiration') in Chekhov in his book Science and the Stanislavsky Tradition of Acting $(2006,9)$.

37 Circle walk (chankramanam) is considered one of the ancient techniques of Tantric origin practiced in various Hindu and Buddhist schools. It is also believed that Christian and Sufi monks used to practice circle walk. One version of the practice is available in Kriya Yoga and Osho prescribes a slightly different version.

${ }^{38}$ Bachelard, The Poetics of Space, 234.

39 Ibid., 239.

${ }^{40}$ Carnicke, Stanislavsky in Focus, 61.

41 Tattu-Marma literally means striking the vital points in the body. The practice of the martial art is found as part of the local medical tradition known as Marma, which is based on the vital points of the body. Marma literally means vital or lethal and striking those points will bring disorders to the body. There are 108 marma points in the body, and Tattu-Marma movements are designed to strike those points.

42 Simonsen, "Bodies, Sensations, Space” 4.

43 Ibid., 7-8.

44 Ibid., 9.

45 Levin, "Aesthetic movements", 199.

46 Bogue, Deleuze on Music, 125.

47 Deluze, Francis Bacon, 34-35.

48 Ibid., 165.

49 Deluze, Francis Bacon, 34-35.

50 Benedetti, Work on a Role, 166.

51 Ibid. 


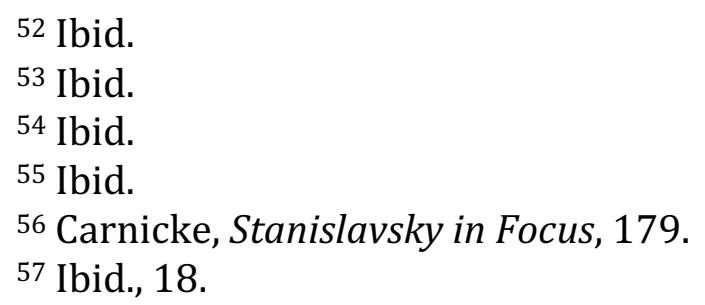

\section{Bibliography}

Bachelard, Gaston. The Poetics of Space. Boston: Beacon Press, 2012.

Benedetti, Jean. An Actor's Work. London \& New York: Routledge, 2008.

Benedetti, Jean. An Actor's Work on a Role. London \& New York: Routledge, 2010.

Bogue, Roland. Deleuze on Music, Painting and the Arts. New York: Routledge, 2003.

Carnicke, Sharon. Stanislavsky in Focus. London \& New York: Routledge, 2009.

Carnicke, Sharon. "The life of the Human Spirit: Stanislavsky's Eastern Self." In Teatr: Russian Theatre Past and Present, Vol. 1, 3-14, 2000.

Deleuze, Gilles. Francis Bacon: The Logic of Sensation. Translated by. D. W. Smith. London: Continuum, 2005.

Feuerstein, Georg. The Yoga-Sutra of Patanjali. Kent: Dawson, 1979.

Feuerstein, Georg. Text Book of Yoga. London: Rider and Company, 1975.

Irigaray, Luce. Between East and West: From Singularity to Community. Translated by Stephen Pluháček. New York: Columbia University Press, 2002.

Lefebvre, Henri. The Production of Space. Oxford: Blackwell, 1991.

Levin, Kasper. "Aesthetic movements of Embodied Minds: Between Merleau-Ponty and Deleuze." Continental Philosophy Review, 49, (2016), 181-202.

Magarshack, David. Stanislavski: A Life. New York, 1951.

Malville, J. McKim. "Astrophysics, Cosmology, and the Inner Space of Indian Myths and Temples." In Concepts of Space: Ancient and Modern, edited by Kapila Vatsyayan, New Delhi: Indira Gandhi National Centre for the Arts, 1991.

Merleau-Ponty, Maurice. Phenomenology of Perception. London: Routledge \& Keegan Paul, 1962.

Merleau-Ponty, Maurice. The Visible and the Invisible, Evanston: Northwestern University Press, 1992. 
Nair, Sreenath. Restoration of Breath: Consciousness and Performance. Amsterdam and New Yotk: Rodopi, 2007.

Pitches, Jonathan. Science and Stanislavsky Tradition of Acting. London: Routledge, 2006.

Simonsen, Kristen. "Bodies, Sensations, Space and Time: The Contribution from Henri Lefebvre." Swedish Society for Anthropology and Geography, 87 B, no. 1 (2005): 1-14.

Tcherkasski, Sergei. Stanislavsky and Yoga. London \& New York: Routledge, 2016.

Vatsyayan, Kapila. The Square and Circle of the Indian Arts. New Delhi: Abhinav Publications, 1979.

William H. Wegner, "The creative circle: Stanislavski and Yoga." Educational Theatre Journal, 28, no.1 (March 1976): 85-90. 